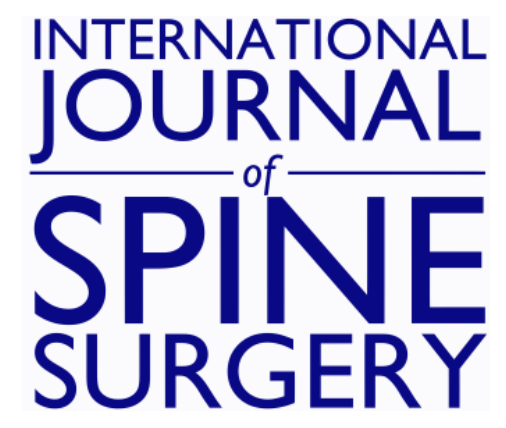

\title{
Comparison of quality of life between men and women who underwent Transforaminal Percutaneous Endoscopic Discectomy for lumbar disc herniation
}

Stylianos Kapetanakis, Grigorios Gkasdaris, Tryfon Thomaidis, Georgios Charitoudis and Konstantinos Kazakos

Int J Spine Surg 2017, 11 (4)

doi: https://doi.org/10.14444/4028

http://ijssurgery.com/content/11/4/28

This information is current as of April 25, 2023.

Email Alerts Receive free email-alerts when new articles cite this article. Sign up at:

http://ijssurgery.com/alerts

The International Journal of Sding Surgehth: 2397 Waterbury Circle, Suite 1 ,

Aurora, IL 60504, Phone: +1-630-375-1432

(C) 2017 ISASS. All Rights Reserved. 


\section{Comparison of quality of life between men and women who underwent Transforaminal Percutaneous Endoscopic Discectomy for lumbar disc herniation}

Stylianos Kapetanakis, MD, PhD, Grigorios Gkasdaris, Tryfon Thomaidis, Georgios Charitoudis, Konstantinos Kazakos

European Interbalkan Medical Center

\section{Abstract}

Background

Studies describing the efficacy of TPED on shortness of recovery and improvement of postoperative quality of life are limited, especially regarding gender something that has never been reported before in the literature. The purpose of this study is to evaluate possible differences of the health-related quality of life in patients who underwent TPED for LDH in accordance with sex.

\section{Methods}

Seventy-six patients diagnosed and treated with TPED for LDH with 1 year follow-up were selected and divided into two groups of equal number depending on sex. Their quality of life was evaluated by using the SF-36 before the operation, six weeks, three, six and twelve months postoperatively. A statistical analysis was conducted, in order to compare the 8 scaled scores of the SF-36 combining each time two chronological phases in the total of patients, in each group and between groups.

Results

Fifty-two $(68.4 \%)$ patients were $\leq 63$ years old, while the rest $24(31,4 \%)$ were $>63$ years old (mean $\pm \mathrm{SD}=56,5 \pm 12,1$ years). Apart from the PF domain, the scores were higher in every visit for the two groups, but the change between groups was not significant. Women had a significantly higher increase of PF score in 3 months after TPED and in the interval 6 weeks- 3 months comparing with men. However, in the intervals 3 months- 6 months and 3 months- 12 months men presented significantly higher increase compared to women.

\section{Conclusions}

Statistically significant improvement of the quality of life for both men and women was observed. Generally, there was no significant difference between the two groups. As regards to the physical functioning, it appears to be a significant difference which is counterpoised over time.

Level of evidence

2.

Clinical relevance

TPED for LDH does not present major differences in the improvement of quality of life regarding gender.

ENDOSCOPIC MINIMALLY INVASIVE SURGERY

KEYWORDS: LUMBAR DISC HERNIATION, TRANSFORAMINAL PERCUTANEOUS ENDOSCOPIC DISCECTOMY, MINIMALLY INVASIVE SPINE SURGERY, GENDER, QUALITY OF LIFE, SF-36

VOLUME 11 ISSUE 4 DOI: $10.14444 / 4028$

PAGES $218-228$

\section{Introduction}

Lumbar disc herniation (LDH) is more common in the lower levels of lumbar spine and responsible for the presence of the lumbosacral radicular syndrome which is a frequently observed problem. ${ }^{1}$ The major symptoms of this syndrome are the low back pain and sciatica following a dermatomal pattern from below the knee till the feet and toes. Low back pain and sciatica is the main cause of disability and one of the 
most prevalent diseases affecting the majority of population on both health and socioeconomics. ${ }^{2,3,4}$ Without treatment for a long period of time, it is responsible for relapses of pain and high frequency of work absence. ${ }^{5}$ Low back pain is more frequent in men, but the prevalence is quite high in both sexes. ${ }^{6}$ Other symptoms of the lumbosacral syndrome may include unilateral spasm of the paraspinal muscles, gait deformity, limited forward flexion, muscle weakness and reflex changes. ${ }^{7,8}$

In patients with persistent or progressive symptoms after 6 to 12 weeks of conservative treatment (by analgesics or by physical therapy), surgery is indicated. Surgical approach to treatment of $\mathrm{LDH}$ includes open discectomy and microdiscectomy. ${ }^{910}$ Although discectomy is the most frequently performed spinal surgery, it has been replaced by microdiscectomy, which is now the gold standard method. ${ }^{11,12,13} \mathrm{Im}$ provements in the use of optics and surgical instruments have led to the utilization of full-endoscopic minimally invasive surgical procedures. As a result, endoscopy has become popular among spinal surgeons the last decades and can be performed with a posterior or posterolateral approach. ${ }^{14}$ The search for newer surgical techniques to achieve the aims of MIS, including limited skin incision and decreased muscle damage, has made transforaminal percutaneous endoscopic discectomy (TPED) a promising MIS procedure recently.

Transforaminal percutaneous endoscopic discectomy approaches the epidural space through the Kambin's triangle and combines the benefits of endoscopy (direct visualization, reduced trauma, reduced blood loss, shorter hospital stays, less pain, quicker recovery and postoperative morbidity with optimal exposure of the intervertebral space and preservation of the dorsal musculature, the vertebrae and the ligamentous structures. ${ }^{15,16,17}$ No paraspinal muscle is cut or detached from the insertion. The minimal tissue damage during TEPD could make a difference in effectiveness, faster rehabilitation and thus lower costs for society. There are several studies comparing the safety and efficacy of TEPD with those of microdiscectomy, however there is no comparison between men and women who underwent this minimally invasive surgery. Men contrary to women have generally greater muscle mass, but slightly higher BMI which could hypothetically alter the post-surgical recovery. Thus, we considered that some differences based on gender characteristics might exist between our two groups. This study examines our experience using this technique to improve early recovery after surgery treating LDH in accordance with sex.

\section{Patients and Methods}

\section{Patients}

All patients of our study were diagnosed with LDH and they had filled all the indications for discectomy. The total of patients was referred to the same orthopaedic spine surgeon and all the procedures were performed at the same hospital. Patients agreed to participate in the study and signed a fully informed written consent. The study was approved by the medical council of the hospital and the local ethics committee.

Inclusion criteria were: (i) radiculopathy (ii) positive nerve root tension sign (iii) sensory or motor neurologic lesion on clinical examination (iv) hernia confirmed by MRI of the lumbar spine, in compliance with clinical findings (v) failure of 12-weeks conservative treatment.

Exclusion criteria were: (i) non-contaminated disc hernia exceeding the one third of the spinal canal on the sagittal MRI scans (ii) sequestration of the disc (iii) central or lateral recess spinal stenosis (iv) recurrent herniated disc or previous surgery at the affected level (iii) segmental instability or spondylolisthesis (iv) spinal tumor or infection (v) vertebral fracture.

\section{Methods}

This is a prospective cohort study involving patients who underwent TPED for LDH. In general, 103 patients underwent spine surgery throughout 2014-2015. From them, 76 patients were selected to participate in a 1 year follow-up and they were divided in two groups according to the sex. Their healthrelated quality of life was evaluated by using the Short Form (36) Health Survey (SF-36). Patients were asked to complete the measurements right be- 
fore surgery. The 8 dimensions of the SF-36, including physiological function (physical functioning, $\mathrm{PF}$ ), physical function (role-physical, RP), bodily pain (bodily pain, BP), general health (general health, GH), energy (vitality, VT), social function (social functioning, SF), emotional function (roleemotional, RE) and mental health (mental health, $\mathrm{MH}$ ), were measured and re-assessed at 6 weeks, 3 months, 6 months and a year after the TPED. Our primary hypothesis was that some of the 8 scaled scores of SF 36 would differ significantly, between men and women a year after TPED.

\section{Surgical Technique}

The TEPD was performed under local anesthesia and mild sedation. All patients were monitored in terms of blood pressure, pulse rate, oxygen saturation and electrocardiographic signals. Patients were positioned at the lateral decubitus position, lying down on the opposite site in order the lesion to face upwards..$^{14}$ After the disinfection of the surgical field, local anesthesia was initially performed at the needle entry site. The needle was placed through the Kambin's triangle $11 \mathrm{~cm}$ of the midline, under fluoroscopic technique ${ }^{14,18}$ (Figure 1). After verification of the level, mild sedation and analgesia were provided with fentanyl (Fentanyl ampule), because the enlargement of the neural foramen is painful. The compliance of the patients was affected during the sequential passage of 3 different size reamers $(5.5,6.5,7.5 \mathrm{~mm}$, Joimax System). The cannula and the endoscope were, then, placed and the nerve root was secured. Subsequently, the discectomy was performed with graspers (Figure 2). The patients were monitored for the following hour in the wards and, then, mobilized.

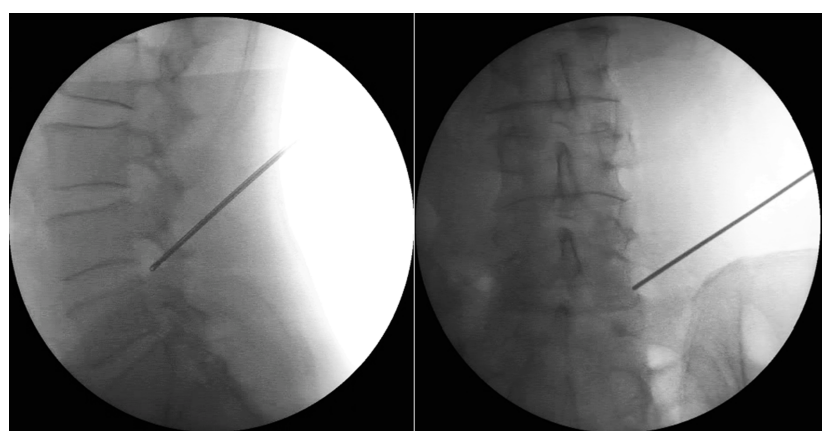

Fig. 1. Anteroposterior (right) and lateral (left) intraoperative fluoroscopic images of the guidewire placed at the level where the disc herniation is present.

\section{SF-36 Scoring Scale}

The scale has 36 items. The item 2 is self-reported health changes and does not participate in scoring. The remaining 35 entries constitute 8 dimensions, $\mathrm{PF}, \mathrm{RP}, \mathrm{BP}, \mathrm{GH}, \mathrm{VT}, \mathrm{SF}, \mathrm{RE}$, and $\mathrm{MH}$. The higher the total score of all these 8 dimensions, the better the quality of life survey. If respondents answer less than half of the number of entries then their questionnaires were considered invalid. ${ }^{19}$

\section{Statistical Analysis}

The statistical analysis of this study was performed with the statistical package SPSS, version 17.00 (SPSS Inc, Chicago, IL). The p-value $<0.05$ was determined as statistically significant difference level. Continuous variables (age, SF-36 score) are expressed as mean \pm standard deviation $(\mathrm{SD})$ and categorical variables (gender) as percentages. We used Student's $t$ test and Mann-Withney U-test for quantitive-continuous variables, for normal or not distribution respectively, and Wilcoxon signed-rank test for repeated measurements on a single sample [Total of patients, Group A (men) and Group B (women)] to assess whether their mean ranks differ in each one of the 8 scaled scores. SF-36 measures were assessed before the operation, 6 weeks, 3 months, 6 months and a year after the TPED. We studied if there was any significant difference at the 8 scaled scores of SF-36 between two chronological phases in the total of patients, in each group and between groups.

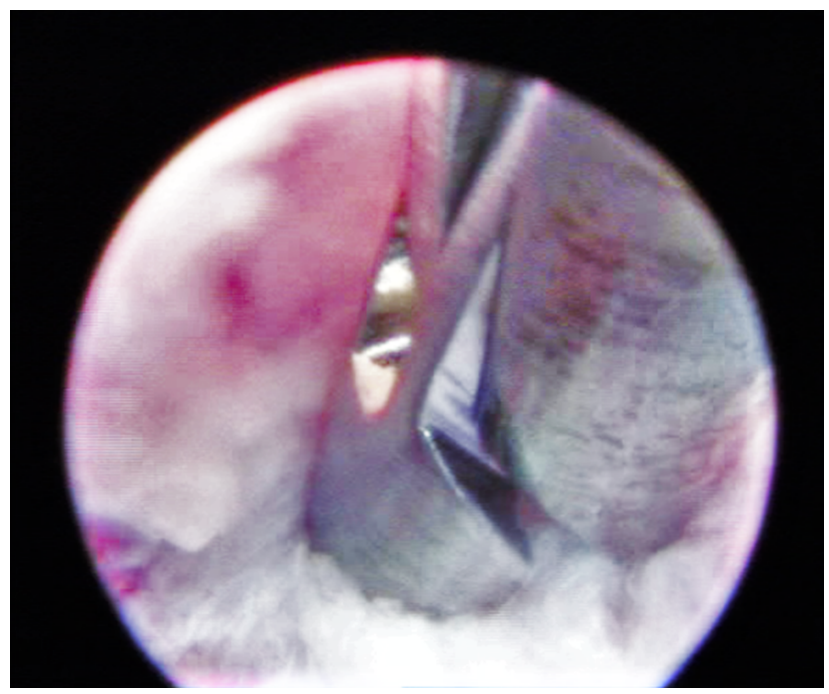

Fig. 2. Intraoperative endoscopic visualization of the annular opening of the working channel.With the rongeur it is possible to remove the herniated disc material. 


\section{Results}

Group A consisted of 38 (50\%) male patients, included patients who had been diagnosed with $\mathrm{LDH}$ and Group B consisted of 38 (50\%) female patients, included patients who had been diagnosed with LDH as well. Referring to the LDH level, 21 (27.6\%) was presented at L3-L4, 40 (52.6\%) at L4-L5 and 15 (19.7\%) at L5-S1 (Table 1). Out of 76 patients, 52 (68.4\%) patients were $\leq 63$ years old, while the rest 24 (31.4\%) were $>63$ years old (mean $\pm \mathrm{SD}=56.5 \pm 12.1$ years). The two subpopulations (men and women) do not have statistically significant differences, something which is important because the groups under comparison have similar starting characteristics (Table 2).

The mean BMI was $29.3 \pm 1.2$ for men and $28.8 \pm 1.1$ for women. The mean operative time was $32.1 \pm 2.3$ minutes and the blood loss limited. All patients underwent the procedure successfully without conversion to open surgery. The patients were discharged one day after surgery. There were no intra-operative complications. There were few postoperative complications which were temporary. One patient presented hypoesthesia on the lower extremity, and two presented neurogenic dysfunction which was absent after one month. Additionally, two furcal nerves were found in two patients. None of the patients underwent a revision surgery.

All selected patients successfully reached the end of the follow up. Thus, the percent of the 1 year follow up is $100 \%$.The increase of all 8 scaled scores of SF-36 between 2 chronological phases and in all intervals was statistical important $(\mathrm{p} \leq 0.05)$ in the total

Table 1. Demographic and baseline characteristics.

\begin{tabular}{|c|c|c|c|c|c|c|c|c|c|c|}
\hline & \multicolumn{2}{|c|}{ Count } & \multicolumn{2}{|r|}{ Age } & \multicolumn{2}{|c|}{ L3-L4 } & \multicolumn{2}{|c|}{ L4-L5 } & \multicolumn{2}{|c|}{ L5-S1 } \\
\hline & $\mathrm{N}$ & $\%$ & Mean & SD & $\mathrm{N}$ & $\%$ & $\mathrm{~N}$ & $\%$ & $\mathrm{~N}$ & $\%$ \\
\hline Total & 76 & 100 & 56.47 & 12.066 & 21 & 27.6 & 40 & 52.6 & 15 & 19.7 \\
\hline Male & 38 & 50 & 56.53 & 12.63 & 11 & 28.9 & 20 & 52.6 & 7 & 18.4 \\
\hline Female & 38 & 50 & 56.42 & 11.64 & 10 & 26.3 & 20 & 52.6 & 8 & 21.1 \\
\hline \multicolumn{5}{|c|}{$\mathrm{t}$ test $\mathrm{p}=0.970$} & & & & & \multicolumn{2}{|c|}{ chi square $p=0.944$} \\
\hline
\end{tabular}

Table 2. Preoperative estimation of mean values of SF-36 for men and women.

\begin{tabular}{|c|c|c|c|c|c|c|c|c|}
\hline & \multicolumn{2}{|c|}{ PF preop } & \multicolumn{2}{|c|}{ RP preop } & \multicolumn{2}{|c|}{ BP preop } & \multicolumn{2}{|c|}{ GH preop } \\
\hline & Mean & SD & Mean & SD & Mean & SD & Mean & SD \\
\hline Total & 47.38 & 7.207 & 21.96 & 5.672 & 31.43 & 5.36 & 64.5 & 4.743 \\
\hline Male & 47.68 & 8.441 & 22 & 6.164 & 31.34 & 5.45 & 64.37 & 4.978 \\
\hline \multirow[t]{4}{*}{ Female } & 47.08 & 5.819 & 21.92 & 5.216 & 31.53 & 5.34 & 64.63 & 4.558 \\
\hline & \multicolumn{2}{|c|}{$\mathrm{t}$ test $\mathrm{p}=0.717$} & \multicolumn{2}{|c|}{ U Mann Whitney $p=0.963$} & \multicolumn{2}{|c|}{$\mathrm{t}$ test $\mathrm{p}=0.882$} & \multicolumn{2}{|c|}{ U Mann Whitney $\mathrm{p}=0.988$} \\
\hline & \multicolumn{2}{|c|}{ V preop } & \multicolumn{2}{|c|}{ SF preop } & \multicolumn{2}{|c|}{ RE preop } & \multicolumn{2}{|c|}{ MH preop } \\
\hline & Mean & SD & Mean & SD & Mean & SD & Mean & SD \\
\hline Total & 46.3 & 5.143 & 50.71 & 6.659 & 50.87 & 7.08 & 70.83 & 7.641 \\
\hline Male & 46.39 & 4.659 & 50.76 & 6.284 & 50.89 & 6.88 & 70.79 & 7.868 \\
\hline \multirow[t]{2}{*}{ Female } & 46.21 & 5.648 & 50.66 & 7.099 & 50.84 & 7.37 & 70.87 & 7.513 \\
\hline & \multicolumn{2}{|c|}{$\mathrm{t}$ test $\mathrm{p}=0.877$} & \multicolumn{2}{|c|}{$\mathrm{t}$ test $\mathrm{p}=0,946$} & \multicolumn{2}{|c|}{$t$ test $p=0.974$} & \multicolumn{2}{|c|}{$\mathrm{t}$ test $\mathrm{p}=0.989$} \\
\hline
\end{tabular}


of patients and in each group separately (Table 3 ). Physical role functioning (PR), bodily pain (BP), general health $(\mathrm{GH})$, vitality $(\mathrm{V})$, social role functioning $(\mathrm{SF})$, emotional role functioning (RE) and mental health $(\mathrm{MH})$ scores were higher in every visit for the two groups, but the change between groups was not significant $(\mathrm{p}>0.05)$. 
Table 3. Comparison of change of mean values for all chronological phases (two phases each time) for men and women.

\begin{tabular}{|c|c|c|c|c|c|c|}
\hline (mean +-sd) & & Preop to 6 weeks & Preop to 3 Months & Preop to 6 Months & Preop to 12 Months & Six Weeks to 3 Months \\
\hline \multirow[t]{4}{*}{ PF } & male & $16.9+-5.6$ & $22.9+-5.8$ & $32.6+-6.9$ & $35.2+-5.9$ & $6.0+-3.1$ \\
\hline & female & $17.1+-4.4$ & $25.8+-5.2$ & $33.3+-5.3$ & $35.9+-5.1$ & $8.7+-3.0$ \\
\hline & & $t$ test & $t$ test & Mann-Whitney & $t$ test & Mann-Whitney \\
\hline & & $\mathrm{p}=0.87$ & $\mathrm{p}=0.023$ & $\mathrm{p}=0.52$ & $\mathrm{p}=0.58$ & $\mathrm{p}<0.001$ \\
\hline \multirow[t]{4}{*}{ RP } & male & $35.29+-5.0$ & $43.61+-5.84$ & $48.45+-5.75$ & $53.0+-6.33$ & $8.32+-3.30$ \\
\hline & female & $35.63+-3.3$ & $44.0+-3.79$ & $48.66+-3.66$ & $53.11+-3.95$ & $8.37+-2.48$ \\
\hline & & $t$ test & Mann-Whitney & Mann-Whitney & Mann-Whitney & Mann-Whitney \\
\hline & & 0.726 & 0.508 & 0.967 & 0.975 & 0.998 \\
\hline \multirow[t]{4}{*}{ BP } & male & $16.03+-4.42$ & $21.55+-4.91$ & $31.18+-5.52$ & $46.32+-5.71$ & $5.53+-2.03$ \\
\hline & female & $16.0+-3.43$ & $21.16+-4.23$ & $30.71+-5.65$ & $46.16+-5.69$ & $5.16+-1.63$ \\
\hline & & Mann-Whitney & $\mathrm{t}$ test & $\mathrm{t}$ test & $\mathrm{t}$ test & Mann-Whitney \\
\hline & & 0.715 & 0.708 & 0.713 & 0.904 & 0.467 \\
\hline \multirow[t]{4}{*}{ GH } & male & $0.95+-1.66$ & $2.42+-1.57$ & $4.08+-2.37$ & $4.74+-2.48$ & $1.47+-2.53$ \\
\hline & female & $1.00+-1.72$ & $1.89+-2.09$ & $3.55+-3.06$ & $4.53+-2.65$ & $0.89+-2.71$ \\
\hline & & Mann-Whitney & Mann-Whitney & Mann-Whitney & Mann-Whitney & Mann-Whitney \\
\hline & & 0.857 & 0.234 & 0.725 & 0.962 & 0.411 \\
\hline \multirow[t]{4}{*}{ v } & male & $11.92+-3.42$ & $17.0+-4.55$ & $30.0+-5.88$ & $33.34+-6.02$ & $5.08+-2.39$ \\
\hline & female & $12.05+-2.56$ & $17.0+-3.65$ & $30.05+-5.20$ & $33.42+-5.60$ & $4.95+-2.82$ \\
\hline & & Mann-Whitney & Mann-Whitney & $t$ test & $t$ test & Mann-Whitney \\
\hline & & 0.549 & 0.782 & 0.967 & 0.953 & 0.745 \\
\hline \multirow[t]{4}{*}{ SF } & male & $13.26+-4.13$ & $15.32+-4.28$ & $29.24+-6.22$ & $33.32+-6.46$ & $2.05+-1.97$ \\
\hline & female & $13.26+-3.68$ & $15.34+-3.92$ & $29.32+-5.08$ & $33.34+-6.37$ & $2.08+-1.68$ \\
\hline & & Mann-Whitney & $\mathrm{t}$ test & $\mathrm{t}$ test & $\mathrm{t}$ test & $t$ test \\
\hline & & 0.917 & 0.978 & 0.958 & 0.986 & 0.95 \\
\hline
\end{tabular}

Downloaded from http://ijssurgery.com/ by guest on April 25, 2023 


\begin{tabular}{|c|c|c|c|c|c|c|}
\hline \multirow[t]{4}{*}{$\mathbf{R E}$} & male & $17.16+-4.99$ & $25.68+-6.41$ & $36.24+-7.06$ & $39.21+-6.59$ & $8.53+-3.74$ \\
\hline & female & $17.18+-5.52$ & $25.66+-5.23$ & $36.26+-5.44$ & $39.26+-5.19$ & $8.47+-3.93$ \\
\hline & & Mann-Whitney & $\mathrm{t}$ test & $\mathrm{t}$ test & $\mathrm{t}$ test & $\mathrm{t}$ test \\
\hline & & 0.843 & 0.984 & 0.986 & 0.969 & 0.953 \\
\hline \multirow[t]{4}{*}{ МH } & male & $1.74+-1.62$ & $4.53+-2.14$ & $7.21+-2.91$ & $9.26+-3.38$ & $2.79+-1.37$ \\
\hline & female & $1.79+-2.00$ & $4.42+-2.52$ & $7.16+-3.15$ & $9.21+-3.86$ & $2.63+-1.42$ \\
\hline & & $t$ test & $t$ test & $t$ test & $t$ test & Mann-Whitney \\
\hline & & 0.901 & 0.845 & 0.941 & 0.951 & 0.673 \\
\hline (mean +-sd) & & Preop to 6 weeks & Preop to 3 Months & Preop to 6 Months & Preop to 12 Months & Six Weeks to 3 Months \\
\hline \multirow[t]{4}{*}{$\mathbf{P F}$} & male & $15.7+-4.5$ & $18.3+-3.5$ & $9.7+-4.3$ & $12.3+-3.5$ & $2.6+-3.1$ \\
\hline & female & $16.2+-3.0$ & $18.8+-3.2$ & $7.5+-3.0$ & $10.1+-3.5$ & $2.6+-1.8$ \\
\hline & & Mann-Whitney & Mann-Whitney & Mann-Whitney & $t$ test & Mann-Whitney \\
\hline & & $\mathrm{p}=0.40$ & $p=0.51$ & $\mathrm{p}=0.025$ & $\mathrm{p}=0.007$ & $\mathrm{p}=0.91$ \\
\hline \multirow[t]{4}{*}{$\mathbf{R P}$} & male & $3.16+-3.69$ & $17.71+-5.04$ & $4.84+-1.89$ & $9.39+-4.78$ & $4.55+-4.43$ \\
\hline & female & $13.03+-2.60$ & $17.47+-3.47$ & $4.66+-1.53$ & $9.25+-3.81$ & $4.45+-2.06$ \\
\hline & & $t$ test & $t$ test & Mann-Whitney & Mann-Whitney & Mann-Whitney \\
\hline & & 0.858 & 0.237 & 0.646 & 0.271 & 0.356 \\
\hline \multirow[t]{4}{*}{ BP } & male & $15.16+-3.65$ & $30.29+-4.75$ & $9.63+-2.84$ & $24.76+-4.80$ & $15.13+-53.78$ \\
\hline & female & $14.71+-3.54$ & $30.16+-4.51$ & $9.55+-2.95$ & $25.0+-4.34$ & $15.45+-4.26$ \\
\hline & & Mann-Whitney & $t$ test & Mann-Whitney & $t$ test & Mann-Whitney \\
\hline & & 0.696 & 0.902 & 0.901 & 0.822 & 0.65 \\
\hline \multirow[t]{4}{*}{ GH } & male & $3.13+-2.98$ & $3.79+-3.12$ & $1.66+-1.83$ & $2.32+-1.87$ & $0.66+-1.80$ \\
\hline & female & $2.55+-3.32$ & $3.53+-3.00$ & $1.66+-1.91$ & $2.32+-1.87$ & $0.97+-1.93$ \\
\hline & & Mann-Whitney & Mann-Whitney & Mann-Whitney & Mann-Whitney & Mann-Whitney \\
\hline & & 0.601 & 0.802 & 0.891 & 0.496 & 0.425 \\
\hline $\mathbf{v}$ & male & $\begin{array}{r}18.08+-4.89 \\
\text { Downloaded from http: }\end{array}$ & $\begin{array}{r}21.42+-5.0 \\
\text { //ijssurgery.com/ by guest on A }\end{array}$ & $13.0+-4.04$ & $16.34+-4.28$ & $3.34+-1.53$ \\
\hline
\end{tabular}




\begin{tabular}{|c|c|c|c|c|c|c|}
\hline & female & $18.0+-4.73$ & $21.37+-5.22$ & $13.05+-3.91$ & $16.42+-4.37$ & $3.37+-1.87$ \\
\hline & & $t$ test & $t$ test & Mann-Whitney & Mann-Whitney & Mann-Whitney \\
\hline & & 0.943 & 0.964 & 0.738 & 0.937 & 0.811 \\
\hline \multirow[t]{4}{*}{ SF } & male & $15.97+-5.89$ & $20.05+-5.86$ & $13.92+-5.43$ & $18.0+-5.41$ & $4.08^{+-1.38}$ \\
\hline & female & $16.05+-4.14$ & $20.08+-5.26$ & $13.97+-3.56$ & $18.0+-4.83$ & $4.03+-2.32$ \\
\hline & & Mann-Whitney & $t$ test & Mann-Whitney & Mann-Whitney & Mann-Whitney \\
\hline & & 0.988 & 0.984 & 0.933 & 0.954 & 0.603 \\
\hline \multirow[t]{4}{*}{ RE } & male & $19.08+-5.59$ & $22.05+-5.64$ & $10.55+-3.95$ & $13.53+-4.09$ & $2.97+-1.78$ \\
\hline & female & $19.08+-4.18$ & $22.08+-4.27$ & $10.61+-2.61$ & $13.61+-3.34$ & $3.00+-2.02$ \\
\hline & & Mann-Whitney & $t$ test & Mann-Whitney & Mann-Whitney & Mann-Whitney \\
\hline & & 0.917 & 0.982 & 0.773 & 0.983 & 0.895 \\
\hline \multirow[t]{4}{*}{ MH } & male & $5.47+-2.33$ & $7.53+-2.78$ & $2.68+-1.31$ & $4.74+-2.22$ & $2.05+-1.52$ \\
\hline & female & $5.37+-2.55$ & $7.42+-3.14$ & $2.74+-2.39$ & $4.79+-3.16$ & $2.05+-1.69$ \\
\hline & & Mann-Whitney & Mann-Whitney & Mann-Whitney & Mann-Whitney & Mann-Whitney \\
\hline & & 0.875 & 0.875 & 0.502 & 0.962 & 0.958 \\
\hline
\end{tabular}


Group B (female) had a significantly higher increase of physical functioning score in 3 months after TPED ( $p=0.023)$ and in the interval from 6 weeks to 3 months $(\mathrm{p}<0.001)$ comparing with Group A (male). However, in the intervals from 3 months to 6 months and from 3 months to 12 months Group A presented significantly higher increase in the physical functioning ( $\mathrm{p}=0.025$ and $\mathrm{p}=0.007$ respectively) compared to Group B. At the end of a year follow up physical function was increased by $35.2( \pm 5.9)$ in group $A$, and $35.9( \pm 5.1)$ in group $B(\mathrm{p}<0.001)$.

Regarding the graphic representations, the SF-36 scores preoperatively, at 6 months and 1 year postoperatively, showed statistically important increase of all 8 domains for men and women separately and in the total of patients (Figure 3, Figure 4). Change in SF-36 scores at 6 months and 1 year compared to before surgery, between men and women, showed no statistically important differences for all 8 domains (Figure 5).

\section{Discussion}

There has been an increasing interest in the effect of gender in scientific and clinical research and we considered this as an interesting comparison, because men contrary to women have generally greater muscle mass but slightly higher BMI which could hypothetically play a significant role in the post-surgical recovery between men and women. The results of this study showed statistically significant improvement of the health-related quality of life, including physical role functioning, bodily pain, general health, vitality, social role functioning, emotional role functioning and mental health, in every postoperative visit for both male and female patients. In general, the change between the two groups was not significant.
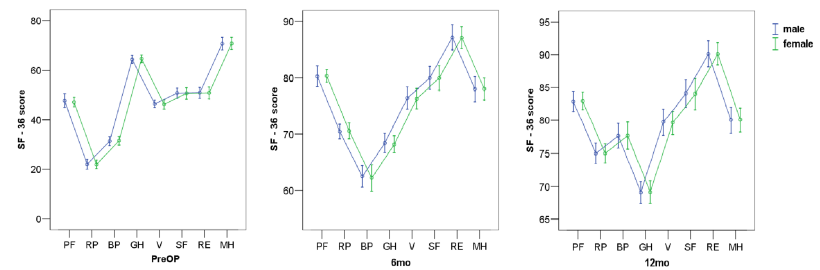

Fig. 3. Preoperatively, at six months and one year postoperatively SF-36 scores, related to gender. PF: physical function, RP: role physical, BP: bodily pain, GH: general health, V: vitality, SF: social function, RE: roleemotional, MH: mental health.
Thus, TPED does not present differences between men and women.

As regards to the $\mathrm{PF}$ domain, women had a significant higher increase of PF score in 3 months after TPED and in the interval of 6 weeks to 3 months, compared to men, however men presented significantly higher increase of $\mathrm{PF}$ score in the last three quarters of the 1-year follow contrary to women. Thus, this difference is counterpoised over time and does not have major clinical importance. $\mathrm{PF}$ domain includes many activities and some of them are vigorous activities (such as running, lifting heavy objects,) moderate activities (such as moving a table), carrying groceries, climbing stairs, bending, walking and other. Probably, men included in this study had more demanding physical functioning in their normal routine than women and also a slightly higher BMI which

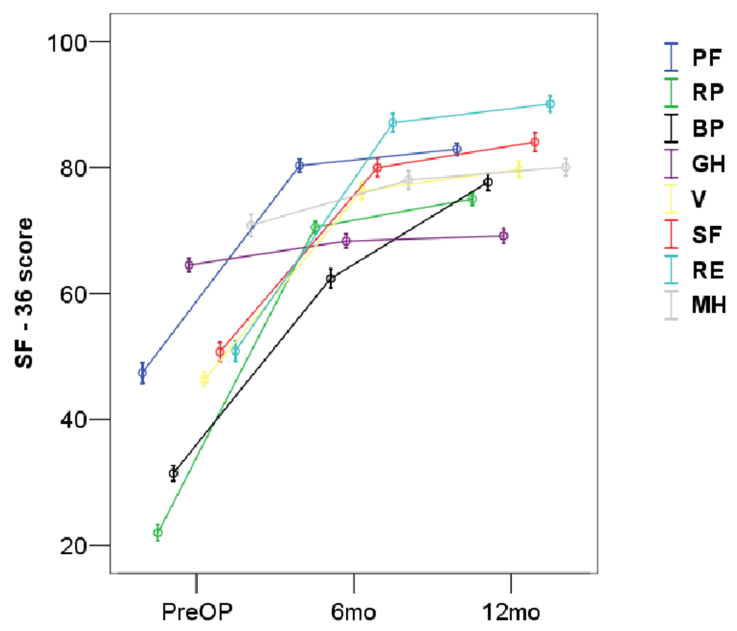

Fig. 4. SF-36 scores in total sample, preoperatively, at six months and one year postoperatively. PF: physical function, RP: role physical, BP: bodily pain, GH: general health, V: vitality, SF: social function, RE: roleemotional, MH: mental health.
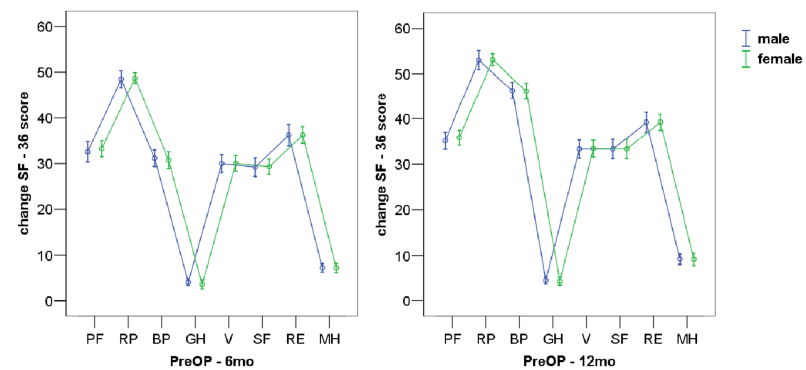

Fig. 5. Change in SF-36 scores at six months and one year compared to before surgery, related to gender. PF: physical function, RP: role physical, BP: bodily pain, GH: general health, V: vitality, SF: social function, RE: roleemotional, MH: mental health. 
leads to more difficulty and limitation of typical activities. Nevertheless, men presented significantly higher increase of PF score in the intervals from 3 months to 6 months and from 3 months to 12 months when compared with women. Explanation to this could be the fact that at this point the recovery of the nerve root is completed and the greater muscle mass of men contributes to improvement in former daily activities.

There are several studies which indicate the role of TEPD as a minimally invasive surgery with multiple advantages especially in single level herniations. ${ }^{15,16,17,20}$ However, studies of TEPD for LDH describing its safety and efficacy are limited. There are two systematic reviews which conclude that TPED appears to be a safe and effective intervention for $\mathrm{LDH}$ and has similar clinical outcomes compared to conventional open microdiscectomy. ${ }^{21,22}$ Even more promising results come from a recent systematic review and metanalysis which compares endoscopic discectomy versus open microdiscectomy and founds a significantly higher satisfaction rate in patients who underwent endoscopic discectomy. ${ }^{23}$ Statistically significant and clinically relevant sex differences were found in other studies also. In a relative study for LDH treated with microdiscectomy, at 1-year followup females reported a higher degree of postoperative back and leg pain, and less improvement regarding disability and some aspects of quality of life, however the surgical effect was similar. ${ }^{24}$

The present study has several limitations. Due to the design, there was no proper control group because the objective of this study was not to emphasize the possible advantages of TEPD over other procedures, but to present its early results on the improvement of the quality of life of patients. We did not want to include the widely used Oswestry Low Back Pain Questionnaire (ODI) and Visual Analogue Scale (VAS) because we consider that SF-36 is a multiscaled questionnaire which is more complete including emotional and mental sections. Furthermore, it would increase the significance of our study results if we considered designing 1 more year follow-up to achieve a 2-year. This did not happen because we wanted to present our early clinical findings on these patients.
Even though several studies regarding TPED for the treatment of LDH exist, none of them has investigated the differences of the improvement of the healthrelated quality of life between men and women. TPED is associated with many advantages if we consider that it preserves the biomechanics of the lumbar spine, offers stability to the operated and adjacent level and reduces traumatization of the supportive paraspinal tissues. Based on our findings, TEPD seems to be a secure and efficient technique with significant improvement on the quality of life of men and women during the 1-year follow-up for the treatment of LDH. Indeed, few differences were observed between the two groups, however they had minor clinical impact. Nevertheless, this topic should be further researched with high-quality randomized controlled trials that also assess cost-effectiveness.

\section{References}

1. Konstantinou K, Dunn KM: Sciatica: review of epidemiological studies and prevalence estimates. Spine (Phila Pa 1976) 2008; 33:2464-2472. doi: 10.1097/BRS.0b013e318183a4a2.

2. Nikoobakht M, Yekanineajd MS, Pakpour AH, Gerszten PC, Kasch R. Plasma disc decompression compared to physiotherapy for symptomatic contained lumbar disc herniation: A prospective randomized controlled trial. Neurol Neurochir Pol. 2016; 50:24-30. doi: 10.1016/j.pjnns.2015.11.001.

3. Shaikh M, Östör AJ. Evaluating the patient with low back pain. Practitioner 2015; 259:21-4, 2-3. 4. Andersson GB. Epidemiological features of chronic low-back pain. Lancet 1999; 354:581-5. 5. Hestbaek L, Leboeuf-Yde C, Manniche C. Low back pain: what is the long-term course? A review of studies of general patient populations. European Spine Journal 2003; 12:149-65.

6. Picavet H, Hazes J. Prevalence of self reported musculoskeletal diseases is high. Annals of the Rheumatic Diseases 2003; 62:644-50.

7. Ropper AH, Zafonte RD: Sciatica. $N$ Engl J Med 2015; 372:1240-1248. doi: 10.1056/NEJMra1410151. 8. van Tulder M, Peul W, Koes B: Sciatica: what the rheumatologistneeds to know. Nat Rev Rheumatol 2010; 6:139-145. doi: 10.1038/nrrheum.2010.3.

9. Laxmaiah M, Frank JEF, Vidyasagar P, Kimberly 
AC, Ramsin MB, Joshua AH. Cost Utility Analysis of Caudal Epidural Injections in the Treatment of Lumbar Disc Herniation, Axial or Discogenic Low Back Pain, Central Spinal Stenosis, and Post Lumbar Surgery Syndrome. Pain Physician 2013; 16:129-143 10. Gregory DS, Seto CK, Wortley GC, Shugart CM. Acute Lumbar Disc Pain: Navigating Evaluation and Treatment Choices. Am Fam Physician $2008 ; 78: 835-842$

11. Weinstein JN, Tosteson TD, Lurie JD, Skinner JS, Hanscom B, Tosteson AN, Herkowitz H, Fischgrund J, Cammisa FP, Albert T, Deyo RA. . Surgical vs nonoperative treatment for lumbar disc herniation: the Spine Patient Outcomes Research Trial (SPORT): a randomized trial. JAMA 2006; 296:2441-50.

12. Postacchini F, Postacchini R. Operative management of lumbar disc herniation: the evolution of knowledge and surgical techniques in the last century. Acta Neurochir Suppl 2011; 108:17-21. doi: 10.1007/978-3-211-99370-5_4.

13. Caspar W: A new surgical procedure for lumbar disk herniation causing less tissue damage through a microsurgical approach. Adv Neurosurg 1977; 4:74-77. 10.1007/978-3-642-66578-3 15 14. Brayda-Bruno M, Cinnella P. Posterior endoscopic discectomy (and other procedures). European Spine Journal 2000; 9(1): S024-S029.

15. Mathews HH. Transforaminal endoscopic microdiscectomy. Neurosyrgery Clinics of North America 1996; 7: 59-63.

16. Mayer HM, Brock M. Percutaneous endoscopic lumbar discectomy (PELD). Neurosurg Rev 1993; 16:115-20.

17. Yeung AT, Yeung CA. Minimally invasive techniques for the management of lumbar disc herniation. Orthop Clin North Am 2007; 38(3): 363-72. DOI: 10.1016/j.ocl.2007.04.005

18. Kambin P, Gellman H. Percutaneous lateral discectomy of the lumbar spine A preliminary report. Clin Orthop 1983; 174: 127-32. DOI: 10.1097/ 00003086-198304000-00015

19. Wang S, Fan W, Yu W et al. Analysis on reliability and validity of SF-36 scale in urban residents.
Chinese Journal of Epidemiology 2016; 37:344 -7. doi: 10.3760/cma.j.issn.0254-6450.2016.03.010.

20. Türk CÇ, Kara NN, Biliciler B, Karasoy M. Clinical outcomes and efficacy of transforaminal lumbar endoscopic discectomy. Journal of Neurosciences in Rural Practice. 2015;6:344-8.doi: 10.4103/ 0976-3147.154575.

21. Kamper SJ, Ostelo RW, Rubinstein SM, Nellensteijn JM, Peul WC, Arts MP, et al. Minimally invasive surgery for lumbar disc herniation: a systematic review and meta-analysis. Eur Spine J 2014; 23:1021-1043. doi: 10.1007/s00586-013-3161-2.

22. Nellensteijn J, Ostelo R, Bartels R, Peul W, van Royen B, van Tulder M. Transforaminal endoscopic surgery for symptomatic lumbar disc herniations: a systematic review of the literature. Eur Spine J 2010; 19:181-204. doi: 10.1007/s00586-009-1155-x.

23. Cong L, Zhu Y, Tu G. A meta-analysis of endoscopic discectomy versus open discectomy for symptomatic lumbar disk herniation. Eur Spine $J$ 2016;25(1):134-43. doi: 10.1007/s00586-015-3776-6. 24. Fredrik Strömqvist, Murad Ahmad, Christer Hildingsson, Bo Jönsson \& Björn Strömqvist. Gender differences in lumbar disc herniation surgery, $A c$ ta Orthopaedica 2008; 79:5, 643-649. doi: 10.1080/ 17453670810016669.

\section{Disclosures and COI}

The authors have none to declare.

\section{Corresponding Author}

Stylianos Kapetanakis MD, PhD, Orthopaedic Surgeon - Spine Surgeon, Director of Spine and Deformities, European Interbalkan Medical Center 57001, Thessaloniki, Greece. stkapetanakis@yahoo.gr.

Published 28 November 2017.

This manuscript is generously published free of charge by ISASS, the International Society for the Advancement of Spine Surgery. Copyright @ 2017 ISASS. To see more or order reprints or permissions, see http://ijssurgery.com. 